\title{
Antagonism of the Melanocortin System Reduces Cold and Mechanical Allodynia in Mononeuropathic Rats
}

\author{
Dorien H. Vrinten, ${ }^{1,2}$ Willem Hendrik Gispen, ${ }^{1}$ Gerbrand J. Groen, ${ }^{2}$ and Roger A. H. Adan' \\ Departments of ${ }^{1}$ Medical Pharmacology and ${ }^{2}$ Anesthesiology, Rudolf Magnus Institute for Neurosciences, University \\ Medical Centre Utrecht, 3584 CG Utrecht, The Netherlands
}

\begin{abstract}
The presence of both pro-opiomelanocortin-derived peptides and melanocortin (MC) receptors in nociception-associated areas in the spinal cord suggests that, at the spinal level, the MC system might be involved in nociceptive transmission. In the present study, we demonstrate that a chronic constriction injury $(\mathrm{CCl})$ to the rat sciatic nerve, a lesion that produces neuropathic pain, results in changes in the spinal cord MC system, as shown by an increased binding of ${ }^{125} \mathrm{I}-\mathrm{NDP}-\mathrm{MSH}$ to the dorsal horn. Furthermore, we investigated whether intrathecal administration (in the cisterna magna) of selective $\mathrm{MC}$ receptor ligands can affect the mechanical and cold allodynia associated with the $\mathrm{CCl}$. Mechanical and cold allodynia were assessed by measuring withdrawal responses of the affected limb to von Frey filaments and withdrawal latencies upon immersion in a $4.5^{\circ} \mathrm{C}$ water bath, respectively. We show that treatment with the $\mathrm{MC}$ receptor an-
\end{abstract}

In humans, damage to the nervous system (a peripheral nerve, dorsal root ganglion, dorsal root, or the CNS) can lead to a pain state referred to as neuropathic pain. This syndrome is characterized by spontaneous pain in combination with allodynia (pain evoked by normally nonpainful stimuli) and hyperalgesia (an increased response to painful stimuli). In current clinical practice, several drugs are used to control neuropathic pain, including tricyclic antidepressants (for review, see Ollat and Cesaro, 1995; Kingery, 1997), anticonvulsants (Rosenberg et al., 1997), systemic administration of local anesthetics (Glazer and Portenoy, 1991; Rowbotham et al., 1991), and NMDA receptor antagonists (Backonja et al., 1994; Felsby et al., 1996). Despite this wide range of drugs, the treatment of neuropathic pain is often unsatisfactory and limited by the occurrence of adverse side effects.

Over the past decade, a number of animal models of neuropathic pain have become available, producing symptoms that closely resemble those observed in human neuropathic pain. Research using these preclinical models has yielded an array of potential new analgesics, including different enzyme inhibitors, ion channel blockers, and ligands for various receptors (for review, see Chizh et al., 1999; Yaksh, 1999). Another potential target in the control of pain that has received very little attention is the melanocortin (MC) system. It has been reported previously that central administration of the melanocortins adrenocorticotropic hormone (ACTH) and $\alpha$-melanocyte stimulating hormone $(\alpha-\mathrm{MSH})$ cause hyperalgesia in various pain tests (Bertolini et al., 1979; Sandman and Kastin, 1981; Williams et al., 1986). Furthermore, these peptides have also been shown to antagonize the analgesic effects of morphine and $\beta$-endorphin (Gispen et al., 1976; Wiegant et al.,

\footnotetext{
Received April 6, 2000; revised July 6, 2000; accepted Aug. 9, 2000.

We thank Simone Duis, Nienke Wanders, and Jan Brakkee for technical assistance on the in vivo experiments, and Keith Garner for performing the ${ }^{125} \mathrm{I}-\mathrm{NDP}-\mathrm{MSH}$ in situ binding assay.

Correspondence should be addressed to Dr. Roger A. H. Adan, Department of Medical Pharmacology, Rudolf Magnus Institute for Neurosciences, University Medical Center Utrecht, Universiteitsweg 100, 3584 CG Utrecht, The Netherlands. E-mail: adan@med.uu.nl.

Copyright (C) 2000 Society for Neuroscience $0270-6474 / 00 / 208131-07 \$ 15.00 / 0$
}

tagonist SHU9119 has a profound anti-allodynic effect, suggesting that the endogenous MC system has a tonic effect on nociception. In contrast, administration of the MC4 receptor agonists MTII and D-Tyr-MTII primarily increases the sensitivity to mechanical and cold stimulation. No antinociceptive action was observed after administration of the selective MC3 receptor agonist $\mathrm{Nle}-\gamma$-MSH. Together, our data suggest that the spinal cord MC system is involved in neuropathic pain and that the effects of MC receptor ligands on the responses to painful stimuli are exerted through the MC4 receptor. In conclusion, antagonism of the spinal melanocortin system might provide a new approach in the treatment of neuropathic pain.

Key words: neuropathic pain; chronic constriction injury; allodynia; melanocortins; melanocortin-4 receptor; spinal cord; dorsal horn; in situ ${ }^{125}$ I-NDP-MSH binding
1977; Smock and Fields, 1981). The mechanisms through which these effects were exerted, however, remained unclear because no receptors for these peptides were identified. Only in recent years, five MC receptors (MC-Rs) subtypes have been identified (for review, see Cone et al., 1996; Tatro, 1996), of which the MC3 and MC4 receptors are expressed in the nervous system. Compared with the MC3 receptor, the MC4 receptor has a much more widespread distribution throughout the brain. Moreover, it is the only subtype of which expression has been demonstrated in the spinal cord (Mountjoy et al., 1994). Binding of ${ }^{125}$ I-NDP-MSH, a synthetic $\alpha$-MSH analog, to rat spinal cord demonstrated that the most abundant MC receptor expression is present in the superficial dorsal horn (lamina I and II) and in the gray matter surrounding the central canal (lamina X), areas that are important in nociceptive transmission (van der Kraan et al., 1999). Furthermore, proopiomelanocortin (POMC) mRNA was also demonstrated in spinal cord (van der Kraan et al., 1999), and immunoreactivity for the POMC-derived peptides $\beta$-endorphin, ACTH, and $\alpha$-MSH has been described in the dorsal horn and lamina X (Tsou et al., 1986; Plantinga et al., 1992). Together, these findings suggest the presence of a functional MC system in the rat spinal cord. Considering the localization of ${ }^{125}$ I-NDP-MSH binding in nociceptionassociated areas in the spinal cord and the fact that the MC4 receptor is the only $\mathrm{MC}$ receptor subtype for which mRNA has been detected in the spinal cord, the spinal MC4 receptor might be a potential target in the ongoing search for new analgesics.

As recently selective ligands for the $\mathrm{MC}$ receptors became available, it is now possible to study a putative role for the MC4 receptor in the control of neuropathic pain. The aim of the present study was to investigate whether changes in the spinal cord MC system play a role in neuropathic pain. Therefore, in situ binding of ${ }^{125}$ I-NDPMSH to rat lumbar spinal cord sections was quantified. The chronic constriction injury (CCI) (Bennett and Xie, 1988) was chosen because of its wide acceptance as a reliable and reproducible model for neuropathic pain. In addition, we investigated whether selective $\mathrm{MC}$ receptor ligands can alter the response of control and mononeuropathic rats to painful stimuli.

We demonstrate that a CCI results in an increase in ${ }^{125} \mathrm{I}-\mathrm{NDP}$ - 
Table 1. Affinity ( $\mathrm{Ki})$ and potency $\left(\mathrm{EC}_{50}\right)$ of melanocortin receptor ligands for the rat $\mathrm{MC3}$ and $\mathrm{MC4}$ receptors

\begin{tabular}{|c|c|c|c|c|}
\hline \multirow[b]{2}{*}{ Ligand } & \multicolumn{2}{|l|}{ Rat MC3 } & \multicolumn{2}{|l|}{ Rat MC4 } \\
\hline & $\mathrm{Ki}(\mathrm{nM})$ & $\mathrm{EC}_{50}(\mathrm{nM})$ & $\mathrm{Ki}(\mathrm{nM})$ & $\mathrm{EC}_{50}(\mathrm{nM})$ \\
\hline MTII & $4.77 \pm 2.13$ & $0.78 \pm 0.17$ & $1.74 \pm 0.77$ & $0.01 \pm 0.004$ \\
\hline D-Tyr-MTII & $204 \pm 87.2$ & $20.3 \pm 7.1$ & $3.84 \pm 0.84$ & $0.47 \pm 0.19$ \\
\hline Nle- $\gamma$-MSH & $1.44 \pm 0.26$ & $1.26 \pm 0.10$ & $77.5 \pm 37.7$ & $11.0 \pm 3.92$ \\
\hline SHU9119 & $0.879 \pm 0.170$ & & $0.238 \pm 0.060$ & \\
\hline
\end{tabular}

Affinities and potencies are determined on HEK 293 cells expressing either the rat MC3 or the rat MC4 receptor using ${ }^{125} \mathrm{I}-\mathrm{NDP}-\mathrm{MSH}$ as radioligand (for $\mathrm{Ki}$ ) or the $\mathrm{LacZ}$ reporter gene (for $\mathrm{EC}_{50}$ ). Data are expressed as mean $\pm 95 \%$ confidence interval (adapted from Adan et al., 1999).

MSH binding to the spinal cord, suggesting an increase in MC receptor levels. We also show that, in CCI rats, intrathecal administration of the MC receptor antagonist SHU9119 induced a decreased sensitivity to cold and mechanical stimulation, whereas the strong MC receptor agonist MTII or the more selective MC4 receptor agonist D-Tyr MTII had the opposite effect. In contrast, in control rats, these ligands had no effect on sensitivity. Furthermore, we show that treatment with the selective MC3-R agonist Nle- $\gamma$ MSH had no effect on sensitivity.

\section{MATERIALS AND METHODS}

\section{Peptides}

For in vivo administration, MTII [Melanotan-II or cyclo-[Nle ${ }^{4}, \mathrm{Asp}^{5}$, D-Phe ${ }^{7}$, Lys $\left.^{10}\right] \alpha$-MSH-(4-10)], SHU9119 [cyclo-[Nle ${ }^{4}$, Asp $^{5}$, D-Nal(2) Lys $\left.^{10}\right] \alpha$-MSH-(4-10)], D-Tyr-MTII (cyclo-[Nle ${ }^{4}$, Asp $^{5}$, D-Tyr ${ }^{7}$, Lys $\left.^{10}\right] \alpha-$ MSH-(4-10)], and Nle- $\gamma$-MSH (Ac-[Nle $\left.{ }^{3}\right]-\gamma_{2}-\mathrm{MSH}_{-} \mathrm{NH}_{2}$ ) were used. MTII was purchased from Bachem Feinchemicalien (Buberdorf, Switzerland), and SHU9119, Nle- $\gamma$-MSH, and D-Tyr-MTII were synthesized using g-fluorenyl methoxycarbonyl solid phase synthesis as reported previously (Schaaper et al., 1998). Peptides were purified using reverse-phase preparative HPLC to a purity of $\pm 90 \%$, estimated after analysis by analytical HPLC at $215 \mathrm{~nm}$. Molecular weight was confirmed by mass spectrometry performed on a Micromass Quattro single quadrupole. Potencies and affinities of these four peptides for the rat MC3 and MC4 receptor are shown in Table 1.

For in situ melanocortin binding to spinal cord cryosections, ${ }^{125} \mathrm{I}-\mathrm{NDP}-$

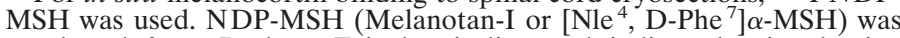
purchased from Bachem Feinchemicalien and iodinated using bovine lacto-peroxidase (Calbiochem, Lucerne, Switzerland) and ${ }^{125} \mathrm{I}-\mathrm{Na}$ (ICN Biochemicals, Costa Mesa, CA) as described previously (Huang et al., 1997), followed by HPLC purification on a C18 column ( $\mu$ Bondapak $3.9 \times$ $300 \mathrm{~mm}$; Waters, Milford, MA).

\section{Animals}

Fifty-nine male Wistar rats weighing 200-240 gm at the start of the study were used. Animals were housed in groups of two to three in plastic cages on a sawdust bedding. They were kept at a $12 \mathrm{hr}$ light/dark cycle, with food and water available ad libitum. All testing procedures in this study were performed according to the Ethical Guidelines of the International Association for the Study of Pain (Zimmermann, 1983) and were approved of by the Ethics Committee on Animal Experiments of the Utrecht University.

\section{Surgery}

Animals were anesthetized with a single subcutaneous injection of Hypnorm (Janssen Pharmaceutical Ltd., Grove, Oxford, UK) containing 0.315 $\mathrm{mg} / \mathrm{ml}$ fentanyl citrate and $10 \mathrm{mg} / \mathrm{ml}$ fluanisone, at a dose of $0.3 \mathrm{ml} / \mathrm{kg}$ bodyweight.

In 33 animals, the right sciatic nerve was exposed at midthigh level by blunt dissection, and a CCI was made by placing four loose ligatures of 4-0 chromic catgut (Ethicon, Norderstedt, Germany) around the nerve, as described previously by Bennett and Xie (1988). In four animals, the same procedure was performed except for placement of the ligatures (sham surgery). After this, the incision was closed with silk sutures, and the animals were allowed to recover. The remaining 22 animals only received a cisterna magna cannula (control animals)

Placement of the cannulas was performed 2 weeks after the sham or CCI lesion. Rats were again anesthetized and placed in a stereotactic frame. The skull was exposed by a midline incision. A steel cisterna magna cannula was inserted through a burr hole just before the squama occipitalis, and two small screws were placed lateral to the midline for extra fixation. Cannula and screws were fastened with dental acrylic. The animals were allowed a $4 \mathrm{~d}$ recovery period before testing was initiated.
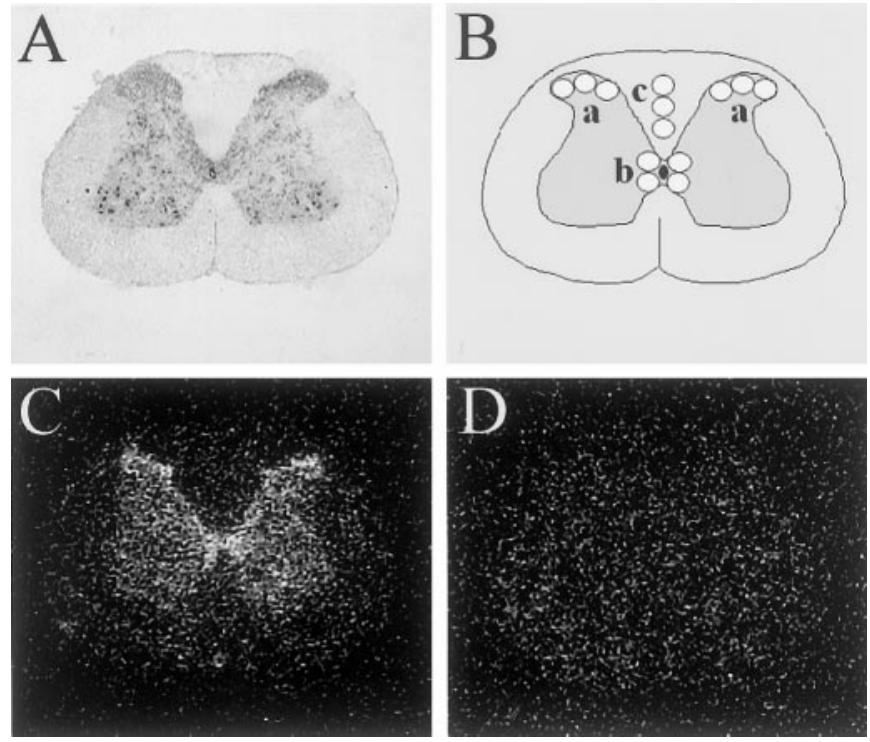

Figure 1. ${ }^{125} \mathrm{I}-\mathrm{NDP}-\mathrm{MSH}$ binding to rat spinal cord sections. $A$, Nissl staining of a representative spinal cord section, demonstrating the neuroanatomy. $B$, Diagram representing the sampling template used for determining ${ }^{125}$ I-NDP-MSH binding in $\mathrm{x}$-ray film autoradiograms of rat spinal cord sections. $a$, Superficial dorsal horn (left and right); $b$, lamina X; $c$, dorsal white matter column used for determining background value. For each region, the mean value of three (superficial dorsal horn and background) or four (lamina X) samples was calculated. $C, D$, x-Ray film autoradiogram of ${ }^{125} \mathrm{I}-\mathrm{NDP}-\mathrm{MSH}$ binding to a representative rat spinal cord section. Sections were incubated with ${ }^{125}$ I-NDP-MSH in the absence $(C)$ or presence $(D)$ of $3 \mu \mathrm{M}$ non-iodinated NDP-MSH. Specificity of binding present in $C$ is demonstrated by its inhibition in $D$.

\section{In situ ${ }^{125}$ I-NDP-MSH binding to spinal cord}

Seven animals that remained naive to treatment (four sham and three CCI animals) were used for in situ ${ }^{125}$ I-NDP-MSH binding.

Tissue preparation. Four weeks after placement of the ligatures or sham surgery, the rats were killed by decapitation. The lumbar spinal cord was rapidly removed and frozen by submersion in 2-methyl-butane (Fluka Chemika, Buchs, Switzerland) on dry ice. Spinal cords were stored at $-80^{\circ} \mathrm{C}$ until further processing. From lumbar segments L4-L6, cryostat sections $(16 \mu \mathrm{m})$ were prepared and mounted on gelatin-coated slides (two sections from each segment per slide).

In situ binding assay. From each animal, one slide was incubated with ${ }^{125}$ I-NDP-MSH as described previously (Tatro, 1993). In short, the sections were prewashed, incubated with ${ }^{125} \mathrm{I}-\mathrm{NDP}-\mathrm{MSH}\left(10^{6} \mathrm{cpm} / \mathrm{ml}\right)$ in binding buffer for $1 \mathrm{hr}$, washed six times to stop binding reactions, and rapid air dried. A second slide from each animal was incubated with ${ }^{125} \mathrm{I}-\mathrm{NDP}-\mathrm{MSH}$ in the presence of $3 \mu \mathrm{M}$ non-iodinated NDP-MSH to determine the specificity of tracer binding. All binding assays were done on the same day, in one experimental session.

To visualize the neuroanatomy more clearly, an adjacent section was Nissl stained (Fig. 1A).

Autoradiography and analysis. Autoradiography was performed by exposing an X-ray film (BioMax MR; Eastman Kodak, Rochester, NY) directly to the slides for 1 week. All slides were run on the same, single film, with CCI and sham samples randomly divided over the film. Autoradiograms were digitized and quantitatively analyzed using the MCID 
(Microcomputer Imaging Device; Imaging Research Inc., St. Catharines, Ontario, Canada). For each section, binding was measured in three anatomic regions, using a sampling template as depicted in Figure $1 B$. Within each region, three or four samples were measured, and the mean value was calculated. Specific binding was calculated by subtraction of the mean background value, determined within the dorsal white matter column of the same section. Absorbance values were converted into counts per minute using a linear calibration curve.

\section{Drug administration}

Thirty CCI and 22 control animals were used to study the effects of the different peptides on nociception. Peptides were dissolved in $10 \mu \mathrm{l}$ of saline and injected through the cisterna magna cannula by means of a Hamilton syringe.

On each testing day, CCI rats were randomly divided into three groups $(n=10$ each), each group randomly and blindly receiving one of the following doses: vehicle, SHU9119, $0.15,0.5$, or $1.5 \mu \mathrm{g}(0.140,0.466$, or $1.40 \mathrm{nmol}$, respectively); MTII, 15, 30, 100, or $500 \mathrm{ng}(14.6,29.2,97.6$, or $488.2 \mathrm{pmol}$, respectively); D-Tyr-MTII, $0.3,1.0$, or $3.0 \mu \mathrm{g}(0.289,0.962$, or $2.885 \mathrm{nmol}$, respectively); Nle- $\gamma$-MSH, $5 \mu \mathrm{g}(3.22 \mathrm{nmol})$ or a combination of $15 \mathrm{ng}$ of MTII and $0.5 \mu \mathrm{g}$ of SHU9119. Thus, in total, 13 groups of 10 CCI animals were tested.

Similarly, on each testing day, control rats were randomly divided in two groups ( $n=11$ each), each group randomly and blindly receiving one of the following doses: vehicle, $1.5 \mu \mathrm{g}$ of SHU9119, $500 \mathrm{ng}$ of MTII, or $3 \mu \mathrm{g}$ of D-Tyr-MTII (corresponding to the highest doses tested in CCI animals). Thus, in total, four groups of 11 control animals were tested.

Using this experimental setup, animals received only a single injection with a single dose on each testing day. The study was continued until all doses of all drugs were tested. Animals were given at least $2 \mathrm{~d}$ rest between drug injections to minimize any possibility of drug interactions or development of tolerance.

\section{Testing procedures}

Temperature stimulation test. Withdrawal latency to a temperature stimulus was measured by immersing the right (experimental) hind paw into a 4.5 or $47.5^{\circ} \mathrm{C}$ water bath. Upon immersion of the paw, an electronic circuit including a timer was closed. Withdrawal of the paw resulted in a discontinuation of the circuit, which stopped the timer, thus allowing a precise registration of the withdrawal latency time. Cutoff time for both temperatures was set at $10 \mathrm{sec}$ to avoid skin damage.

Mechanical stimulation test. Foot withdrawal threshold in response to a mechanical stimulus was determined using a series of von Frey filaments (Stoelting, Wood Dale, IL), ranging from 1.08 to $21.09 \mathrm{gm}$. Animals were placed in a plastic cage with a metal mesh floor, allowing them to move freely. They were allowed to acclimatize to this environment before the experiment. The filaments were presented to the midplantar surface as described by Chaplan et al. (1994), starting with the smallest filament. Each probe was applied to the foot until it just bent, and the smallest filament eliciting a foot withdrawal response was considered the threshold stimulus.

For both mechanical and temperature stimulation tests, baseline values were determined, and measurements were repeated 15,30 , and $60 \mathrm{~min}$ after drug or vehicle administration.

\section{Grooming assay}

In eight CCI animals, a grooming assay was performed as described by Gispen et al. (1975). In short, animals were placed in a plastic observation cage immediately after injection of $500 \mathrm{ng}$ of MTII $(n=4)$ or saline $(n=$ 4) through the cisterna magna cannula. Starting $10 \mathrm{~min}$ after injection, grooming (face washing, genital grooming, body licking and grooming, and scratching and paw licking) was scored every 15 sec. Observation was stopped 50 min after injection.

\section{Data analysis}

All data are expressed as mean \pm SEM for visualization purposes only.

For in situ ${ }^{125}$ I-NDP-MSH binding to spinal cord, the overall mean of levels L4-L6 and one to two sections per rat (thus rendering one data point per anatomic region per rat) were used to calculate group means and SEM. Differences between sham and CCI groups were analyzed using an independent Student's $t$ test.

For the temperature stimulation test, the difference between baseline and postinjection withdrawal latency was calculated for each animal at each time point.

To obtain a linear scale of perceived intensity in the mechanical stimulation test, the logarithm of the withdrawal thresholds was plotted. As for the temperature stimulation test, differences between post-treatment and pretreatment withdrawal thresholds were calculated.

For mechanical and temperature stimulation, differences in baseline values between control and CCI groups and differences between drug treatment groups were analyzed using the Kruskall-Wallis test because of the nonparametric nature of the data. When appropriate, post hoc analysis was performed using the Mann-Whitney $U$ test, comparing each treatment dose with vehicle and for each treatment comparing the highest dose with the intermediate and lowest dose, respectively. A Bonferroni correction was performed.

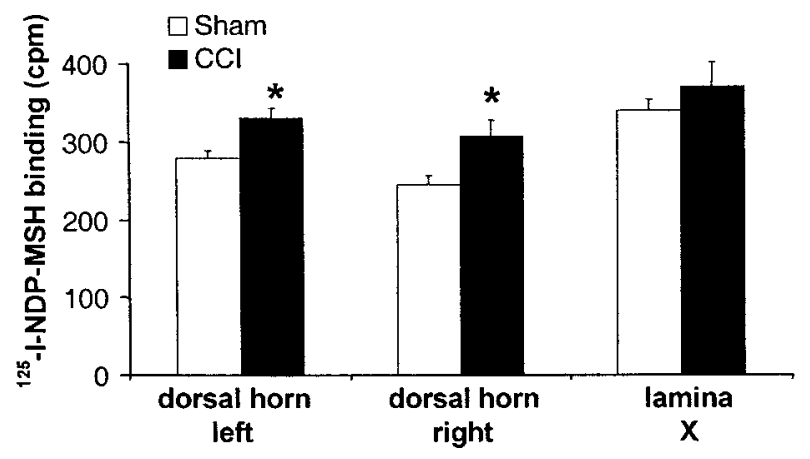

Figure 2. ${ }^{125}$ I-NDP-MSH binding levels in different anatomic regions in rat lumbar spinal cord (L4-L6) cryostat sections. Spinal cords were collected 4 weeks after CCI or sham surgery. Regions were analyzed by sampling the corresponding region of an x-ray film autoradiogram, using a template as depicted in Figure $1 A$. Values were converted to counts per minute using a linear calibration curve. Specific binding within each region was determined by subtracting the mean background value obtained from the dorsal white matter from the same section. For each region, the overall mean of levels L4-L6 from one or two sections was calculated per rat. Data are represented as mean \pm SEM of four $\left(\right.$ sham) or three (CCI) rats. ${ }^{*} p<$ 0.05 versus sham.

Where possible, dose-response curves were generated. Therefore, postinjection values were expressed as a percentage of baseline value. Mean \pm SEM of these percentages were plotted against the administered dose. Dose-response curves are reported for the time of peak effect (30 min after injection for MTII and D-Tyr-MTII, and 15 min after injection for SHU9119).

Differences in grooming scores were analyzed using an independent Student's $t$ test. For all tests, a probability level of $p \leq 0.05$ was the criterion for a significant difference.

\section{RESULTS}

\section{In situ ${ }^{125}$ I-NDP-MSH binding to spinal cord}

Specificity of the ${ }^{125}$ I-NDP-MSH binding is indicated by its inhibition in the presence of $3 \mu \mathrm{M}$ NDP-MSH, which reduced binding to background level (Fig. 1C,D).

As demonstrated previously (van der Kraan et al., 1999), specific ${ }^{125}$ I-NDP-MSH binding was highest in the superficial dorsal horn (corresponding to lamina I-II) and lamina X. In CCI animals, binding in lamina I-II on both the ipsilateral and contralateral sides was significantly increased compared with sham animals (125.5 and $118.7 \%$ of sham values, respectively). In contrast, binding to lamina $\mathrm{X}$ did not differ between groups (Fig. 2).

\section{Baseline values for temperature and mechanical stimulation}

In control animals, the mean baseline mechanical withdrawal threshold for all four groups at all time points was $21.09 \pm 0 \mathrm{gm}$ (mean \pm SEM). In CCI animals, the overall mean baseline was significantly lower $(5.32 \pm 0.21 \mathrm{gm}$, ranging from $4.83 \pm 0.50$ to $6.67 \pm 1.06 \mathrm{gm}$ for the 13 different randomized groups), thus indicating a mechanical allodynia.

At $4.5^{\circ} \mathrm{C}$, overall mean baseline withdrawal latency in control animals was $9.86 \pm 0.06 \mathrm{sec}$ (ranging from $9.75 \pm 0.19$ to $10 \pm 0$ $\mathrm{sec}$ ). In CCI animals, mean baseline withdrawal latency was significantly lower $(6.05 \pm 0.35 \mathrm{sec}$, ranging from $3.47 \pm 0.41$ to $7.36 \pm$ $1.07 \mathrm{sec})$, thus demonstrating a cold allodynia.

At $47.5^{\circ} \mathrm{C}$, overall mean baseline withdrawal latency in control animals was $4.52 \pm 0.22 \mathrm{sec}$ (ranging from $3.57 \pm 0.26$ to $5.47 \pm$ $0.45 \mathrm{sec}$ ). This value was not significantly different from that in CCI animals $(4.66 \pm 0.22 \mathrm{sec}$, ranging from $3.47 \pm 0.41$ to $6.98 \pm 1.26$ $\mathrm{sec})$. These data are shown in Figure 3.

Although baseline values could differ between randomized groups, there was no correlation between these values and administration of either an agonist or antagonist, nor were baseline values consistently changed by previous administration of either an agonist or antagonist (data not shown). 


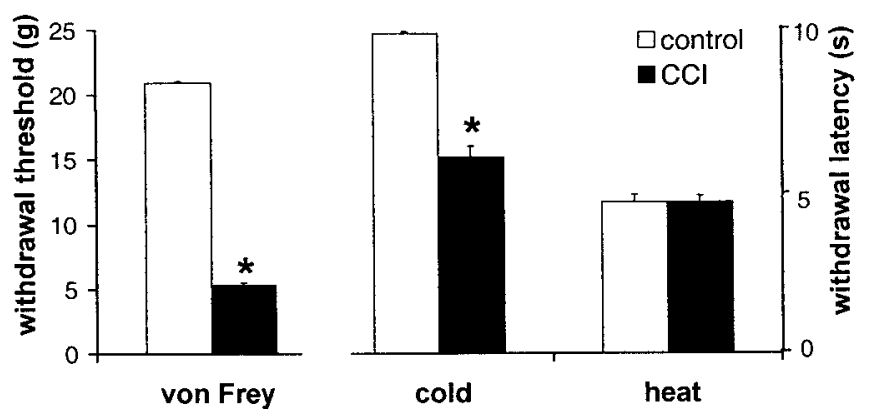

Figure 3. Baseline withdrawal thresholds to von Frey stimulation and baseline withdrawal latencies to cold stimulation $\left(4.5^{\circ} \mathrm{C}\right)$ and heat stimulation $\left(47.5^{\circ} \mathrm{C}\right)$ in control and neuropathic rats. Data are presented as mean \pm SEM of 13 groups of 10 rats (CCI) or 4 groups of 11 rats each (control). ${ }^{*} p<0.05$.

\section{Vehicle injection}

An injection of $10 \mu \mathrm{l}$ of saline through the cisterna magna cannula had no effect on the responses to any of the tests performed, in neither CCI rats nor control rats.

\section{Administration of SHU9119}

In CCI rats, treatment with SHU9119 (0.15, 0.5, and $1.5 \mu \mathrm{g})$ produced a tactile anti-allodynic effect, as shown by a dosedependent increase in withdrawal thresholds to von Frey stimulation (Fig. $4 A$ ) compared with vehicle treatment. Peak effects were reached 15 min after injection, resulting in a withdrawal threshold of up to $170.5 \pm 7.25 \%$ of baseline value (mean \pm SEM) with 1.5 $\mu \mathrm{g}$ of SHU9119 (Fig. 5A).

As for the mechanical withdrawal thresholds, withdrawal latencies to cold stimulation also increased upon administration of SHU9119 (Fig. 6A). The cold anti-allodynic effect of the two lowest doses of SHU9119 showed a dose-dependency as observed for the tactile anti-allodynic effect. However, the highest dose tested (1.5 $\mu \mathrm{g})$ only produced a small increase in withdrawal latencies. This group consisted of only four animals, and baseline withdrawal latencies of two of these four animals were already at cutoff value, leaving no room for a further increase in latency. In the remaining two animals latencies, however, did increase to cutoff value in one case and to $174 \%$ of baseline in the other case. Treatment with SHU9119 did not cause any changes in withdrawal latencies at $47.5^{\circ} \mathrm{C}$ (data not shown).

In control rats, administration of $1.5 \mu \mathrm{g}$ of SHU9119 had no effect on responses to mechanical, cold, or heat stimulation (data not shown).

\section{Administration of MTII and D-Tyr-MTII}

In CCI rats, administration of the MC receptor agonist MTII (15, 30,100 , and $500 \mathrm{ng}$ ) produced a dose-dependent decrease in withdrawal thresholds to mechanical stimulation (Fig. 4B). Thirty minutes after injection, withdrawal thresholds were reduced to $4.64 \pm 0.52 \%$ of baseline (mean \pm SEM) with the highest dose tested (Fig. $5 B$ ).

Similarly as for tactile thresholds, MTII dose-dependently decreased withdrawal latencies at $4.5^{\circ} \mathrm{C}$ (Fig. $6 B$ ). The most potent effect was observed with the highest dose tested, which reduced latencies to $9.68 \pm 5.07 \%$ (mean \pm SEM) of baseline value (Fig. 7). As for SHU9119, treatment with MTII caused no significant changes in withdrawal latency to a heat stimulus.

Administration of the more selective MC4 receptor agonist D-Tyr-MTII produced similar results as those observed with MTII, with $\sim 10$ times higher doses $(0.3,1$, and $3 \mu \mathrm{g})$ resulting in a dose-dependent decrease in withdrawal thresholds to von Frey stimulation (Fig. 4C) and in withdrawal latencies to cold stimulation (Fig. 6C). Values were decreased to $14.73 \pm 6.04$ and $20.04 \pm$ $5.14 \%$ (mean \pm SEM) of baseline values, respectively (Figs. 5B, 7). As for MTII, administration of D-Tyr-MTII had no effect on withdrawal latencies at $47.5^{\circ} \mathrm{C}$.

In control rats, the highest dose of both ligands (500 ng of MTII or $3 \mu \mathrm{g}$ of D-Tyr-MTII) did not cause any changes in responses to mechanical, cold, or heat stimulation (data not shown).

\section{Coadministration of MTII and SHU9119}

Coadministration of $15 \mathrm{ng}$ of MTII, a dose which by itself had no effect on sensory thresholds (Figs. $4 B, 6 B$ ), and $0.5 \mu$ g of SHU9119 in CCI rats resulted in a complete inhibition of the cold and mechanical anti-allodynic effect of SHU9119 (data not shown).

\section{Administration of Nle- $\gamma$-MSH}

In CCI rats, a single, high dose $(5 \mu \mathrm{g})$ of the selective MC3 agonist Nle- $\gamma$-MSH was tested. No decreased or increased response was observed to either mechanical or thermal stimulation (data not shown).

In Figure 8, a summary of the described effects of the different $\mathrm{MC}$ receptor ligands is presented.

\section{Grooming behavior}

Total grooming scores after injection of saline or $500 \mathrm{ng}$ of MTII into the cisterna magna were $50.67 \pm 6.39$ and $54.5 \pm 14.5$, respectively (mean \pm SEM). These values were not significantly different (data not shown).

\section{DISCUSSION}

In the spinal cord, the expression of the MC4 receptor overlaps with that of the POMC-derived peptides $\alpha$-MSH and ACTH (Tsou et al., 1986; van der Kraan et al., 1999) in nociception-associated areas. Therefore, we hypothesized that, at the spinal level, the MC system is involved in the processing of nociceptive information. Here we show for the first time that changes in the spinal cord MC system occur after a CCI to the rat sciatic nerve, a lesion that causes neuropathic pain. As shown in Figure 2, in situ binding of the synthetic MC receptor ligand ${ }^{125} \mathrm{I}-\mathrm{NDP}-\mathrm{MSH}$ is increased in lumbar (L4-L6, corresponding with sciatic nerve input) spinal cord
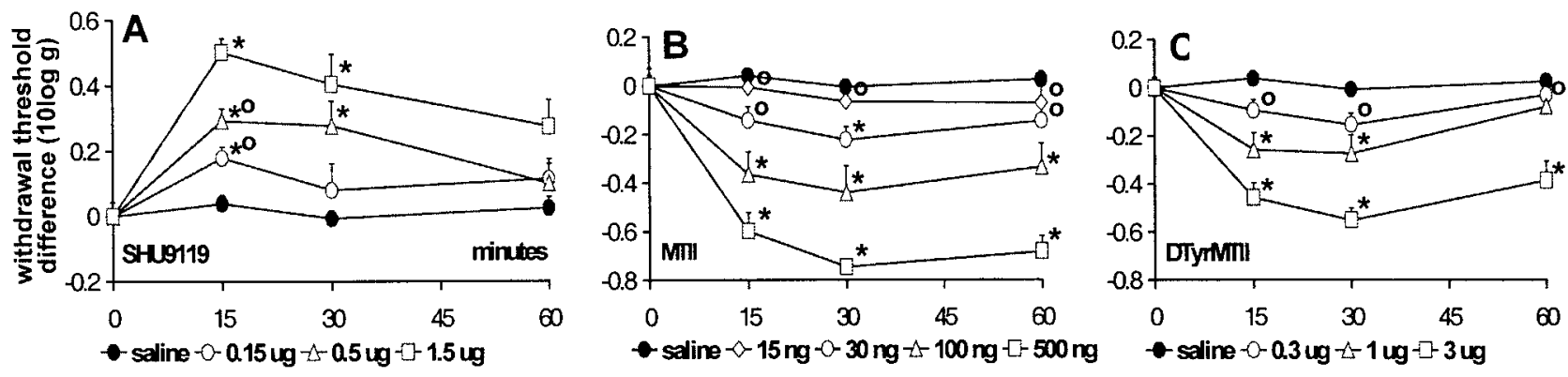

Figure 4. The effect of intrathecal SHU9119 $(A)$, MTII $(B)$, and D-Tyr-MTII $(C)$ on withdrawal thresholds to von Frey stimulation in neuropathic rats. Thresholds are transformed to the logarithm of the applied force. Differences between postinjection and preinjection (baseline) values are plotted. Data are presented as mean \pm SEM of 10 rats each, except $1.5 \mu \mathrm{g}$ of SHU9119 $(n=4) .{ }^{*} p<0.05$ versus vehicle; ${ }^{\circ} p<0.05$ versus highest dose of MTII, D-Tyr-MTII, or SHU9119. 

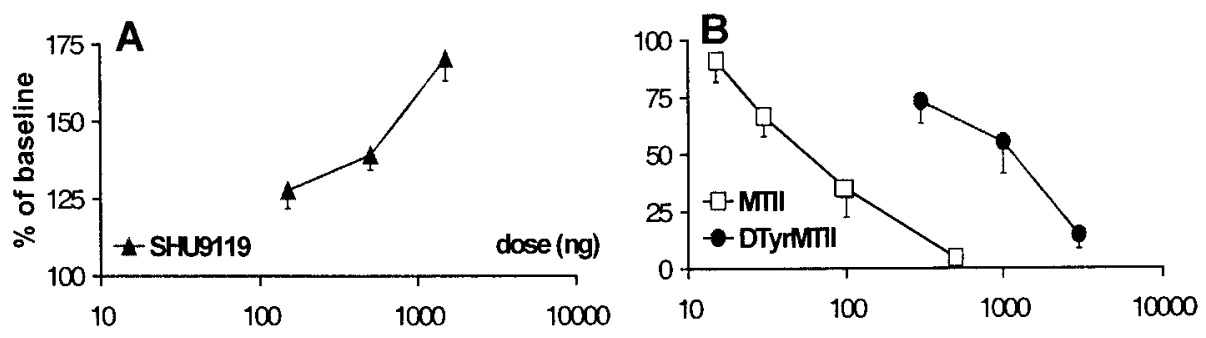

Figure 5. Dose-response curves of the effect of intrathecal SHU9119 $(A)$, MTII $(B)$, and D-TyrMTII $(B)$ on von Frey withdrawal thresholds in neuropathic rats. Values represent threshold at 30 min after injection as a percentage of baseline threshold. Data are presented as mean \pm SEM of 10 rats each, except $1.5 \mu \mathrm{g}$ of SHU9119 $(n=4)$.
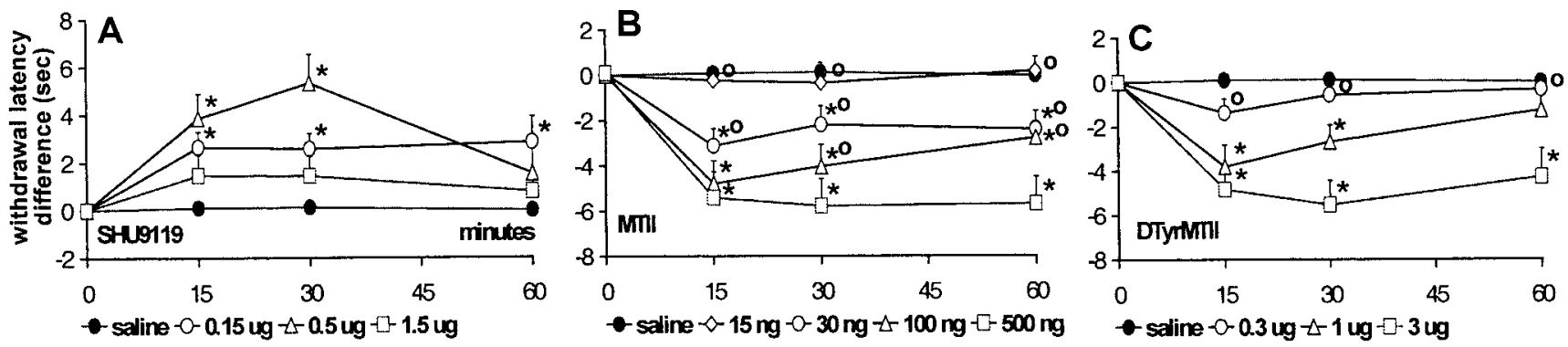

Figure 6. The effect of intrathecal SHU9119 $(A)$, MTII $(B)$, and D-Tyr-MTII $(C)$ on withdrawal latencies to cold stimulation $\left(4.5^{\circ} \mathrm{C}\right)$ in neuropathic rats. Differences between postinjection and preinjection (baseline) values are plotted. Data are presented as mean \pm SEM of 10 rats each, except $1.5 \mu \mathrm{g}$ of SHU9119 $(n=4) .{ }^{*} p<0.05$ versus vehicle; ${ }^{\circ} p<0.05$ versus highest dose of MTII, D-Tyr-MTII, or SHU9119.

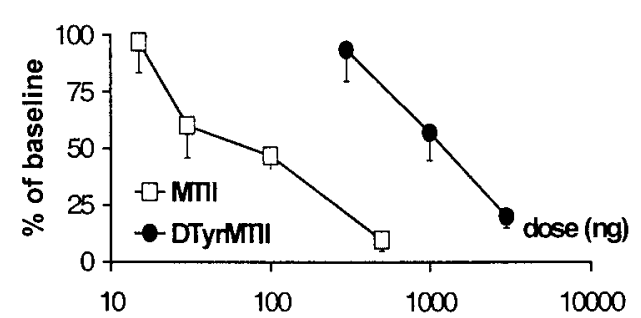

Figure 7. Dose-response curves of the effect of intrathecal MTII and D-Tyr-MTII on withdrawal latencies to cold stimulation $\left(4.5^{\circ} \mathrm{C}\right)$ in neuropathic rats. Values represent threshold at $30 \mathrm{~min}$ after injection as a percentage of baseline threshold. Data are presented as mean \pm SEM of 10 rats each.

sections of CCI rats compared with sham operated animals, suggesting an upregulation of spinal cord MC receptors. It is not likely that these changes are caused by the profound deafferentation associated with a CCI lesion per se (Basbaum et al., 1991; Carlton et al., 1991), because van der Kraan et al. (1999) have shown that crushing the sciatic nerve, another lesion producing extensive nerve fiber loss, did not lead to significant differences in ${ }^{125}$ I-NDPMSH binding levels compared with sham surgery.

Of the anatomic regions we investigated, which were the regions with the highest intensity of binding, the superficial dorsal horn both ipsilateral and contralateral to the lesion showed this increased binding. Bilateral changes associated with CCI have been described for other systems as well, including opioid binding sites (Stevens et al., 1991), calcitonin gene-related peptide and substance $\mathrm{P}$ immunoreactivity (Kajander and $\mathrm{Xu}, 1995)$, metabolic and nitric oxide synthase activity (Mao et al., 1992); (Choi et al., 1996), and transsynaptic degeneration (Hama et al., 1994). The contralateral changes might be explained by changes in primary afferents that cross the midline, commissural connections between intrinsic spinal neurons (Sugimoto et al., 1990), or descending control systems affecting both sides of the spinal cord (Besse et al., 1992).

The superficial dorsal horn, the area that displayed an increased ${ }^{125}$ I-NDP-MSH binding in our experiments, corresponds with the predominant entry zone of cutaneous fine diameter primary afferents of the sciatic nerve. In contrast, the gray matter surrounding the central canal, an area that receives mostly visceral input, showed no differences in binding. These findings suggest that changes in the endogenous MC system in the spinal cord might be involved in the increased pain state associated with the CCI lesion and prompted us to investigate whether tonic activity of the MC system contributed to this increased sensitivity. As shown in Figures 4-6, administration of SHU9119, an antagonist at the MC4 receptor, induced a significant anti-allodynic effect in both the cold and mechanical stimulation tests, indicated by an increased withdrawal latency upon immersion in a $4.5^{\circ} \mathrm{C}$ water bath and a higher threshold to von Frey stimulation, respectively. The observation that administration of an $\mathrm{MC}$ receptor antagonist produced hypoalgesia by itself indeed suggests a tonic influence of the MC system on nociceptive transmission.

The increase in MC receptor level in the superficial dorsal horn in CCI rats suggests an increased sensitivity for MC receptor agonists in neurons in this area. Treatment with the $\mathrm{MC}$ receptor agonist MTII resulted in an opposite effect compared with SHU9119, producing an increased sensitivity to both cold and mechanical stimulation. Similar results were obtained with D-TyrMTII, an MC receptor agonist that displays a higher affinity for the MC4 receptor compared with the MC3 receptor. Coadministration of MTII and SHU9119 demonstrated the specificity of the antiallodynic effect of SHU9119. Injection of $15 \mathrm{ng}$ of MTII, a dose which by itself caused no significant changes in nociceptive thresholds, completely blocked the anti-allodynic effect of $0.5 \mu \mathrm{g}$ of SHU9119 when administered simultaneously, thereby demonstrating that the effects of these compounds are indeed mediated through the same receptor. Administration of the selective MC3 receptor agonist Nle- $\gamma$-MSH had no effect on sensitivity. Because both MTII and D-Tyr-MTII altered the responses to cold and von Frey stimulation whereas Nle- $\gamma$-MSH had no effect, we suggest that the observed changes in nociception are mediated through the MC4 receptor.

In the present study, we administered MC receptor ligands through a cannula placed in the cisterna magna, directly into the fluid surrounding the spinal cord. Adan et al. (1999) have demonstrated that a dose of 4.5 pmol of MTII is already sufficient to induce grooming when administered intracerebroventricularly. In contrast, we demonstrate that a $>100$-fold higher dose $(500 \mathrm{ng}$, $\sim 488$ pmol) failed to induce grooming when injected into the cisterna magna. We cannot exclude the possibility that a small portion of the drugs administered into the cisterna magna will retrogradely reach the ventricular system and surrounding structures and that these structures play a role in the (anti-)nociceptive effects described here. However, because no grooming was ob- 
Figure 8. Summary of the effects of intrathecal. administration of the MC3-R-selective ligand Nle$\gamma$-MSH $(5 \mu \mathrm{g})$, the MC4-R-selective ligands MTII $(500 \mathrm{ng})$ and D-Tyr-MTII $(3 \mu \mathrm{g})$, and the MC-R antagonist SHU9119 $(1.5 \mu \mathrm{g})$ on the responses of $\mathrm{CCI}$ and control rats to different stimuli (indicated on $x$-axis). Values represent thresholds at $30 \mathrm{~min}$ (MTII, D-Tyr-MTII, and Nle- $\gamma$-MSH) or $15 \mathrm{~min}$ (SHU9119) after injection as a percentage of baseline threshold. Data are presented as mean \pm SEM of 11 (control) or 10 (CCI) rats each, except $1.5 \mu \mathrm{g}$ of SHU9119 ( $n=4$ CCI rats).
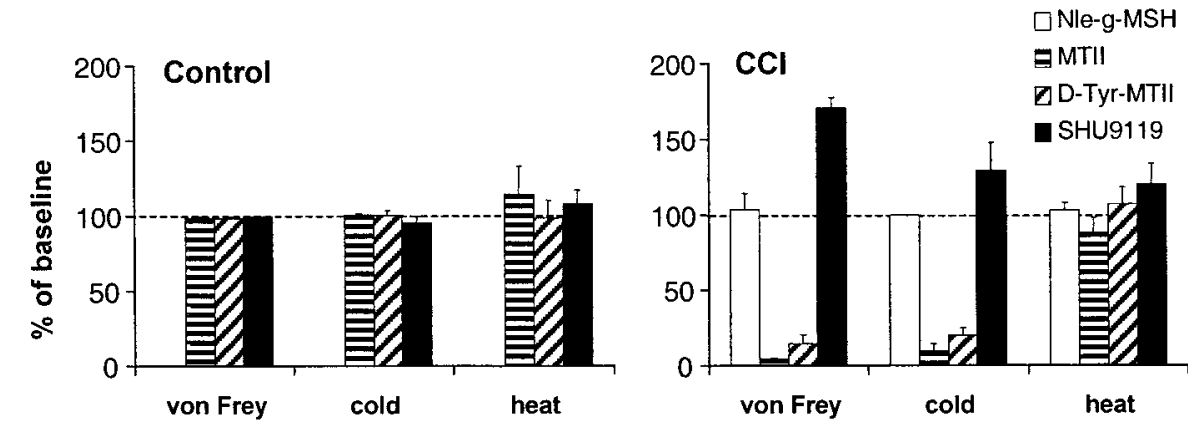

served after injection of a high dose of agonist, we suggest that the effects we observed in the present study are predominantly exerted at the spinal level.

In the dorsal horn, immunoreactivity has been demonstrated for the MC receptor agonists $\alpha-\mathrm{MSH}$ and $\mathrm{ACTH}$, as well as for the opioid peptide $\beta$-endorphin (Tsou et al., 1986), all of which are derived from the POMC peptide. Furthermore, the $\mu$ - and $\delta$-opioid receptor subtypes, for which $\beta$-endorphin displays a high affinity, has also been demonstrated in the same area by immunocytochemistry (Chaplan et al., 1994; Zerari et al., 1994). Therefore, we hypothesize that the observed anti-allodynic effects of SHU9119 might be caused by blockade of a tonic influence of endogenous $\alpha$-MSH on nociception through the MC4 receptor in the spinal cord. This could tip the balance in favor of the anti-nociceptive actions of $\beta$-endorphin, coreleased with $\alpha$-MSH in the same POMC projection areas, thus producing analgesia.

The exact source of spinal POMC expression is not known; it might be intrinsic to the spinal cord (Plantinga et al., 1992; van der Kraan et al., 1999) but may also originate from a supraspinal source, namely the nucleus tractus solitarius (Tsou et al., 1986) or the hypothalamus (Cechetto and Saper, 1988; Elias et al., 1998). Elias et al. (1998) have demonstrated that hypothalamic POMCexpressing neurons innervate the interomedial lateral cell column (IML) at a thoracic level in which sympathetic preganglionic cells are located. In this region, MC4-R mRNA is also expressed (Mountjoy and Wild, 1998).

The melanocortin system is suggested to play a role in the regulation of autonomic function, because centrally administered melanocortins can increase sympathetic nerve activity (Dunbar and $\mathrm{Lu}, 2000$ ), possibly through activation of the MC4 receptor (Mountjoy et al., 1994; Mountjoy and Wild, 1998; Dunbar and Lu, 1999). Although its exact role is still a matter of debate, there are several lines of research indicating that the sympathetic nervous system is involved in neuropathic pain (Price et al., 1989; Kim and Chung, 1991; Shir and Seltzer, 1991; Ringkamp et al., 1999). One of the potential mechanisms by which sympathetic activity influences nociception is through an increased norepinephrine responsiveness in $\mathrm{C}$ fibers, the primary afferents activated by noxious stimuli (for review, see Janig, 1985; Bennett, 1991; Janig et al., 1996).

In this present study, we only demonstrated changes in the MC system in areas of the spinal cord that correspond to sciatic nerve input. We cannot, however, exclude the possibility that changes also occur at other spinal levels or that the ligands we used act through $\mathrm{MC}$ receptors located more rostrally. Thus, an alternative explanation for the observed effects of $\mathrm{MC}$ receptor ligands on neuropathic pain might be a change in sympathetic activity, mediated at the level of the IML.

As shown in Figure 3, baseline values for von Frey and cold stimulation were significantly lower in CCI rats compared with control rats, confirming the development of mechanical and cold allodynia associated with the CCI lesion (Bennett and Xie, 1988; Attal et al., 1990). However, in contrast to other groups (Bennett and Xie, 1988; Attal et al., 1990; Kupers et al., 1992), we observe no differences in sensitivity to noxious heat between control rats and CCI rats. The reason for this discrepancy is not clear but may result from genetic variability between various rat strains. As suggested previously, this may lead to differences in predisposition for the development of neuropathic conditions (Wiesenfeld-Hallin et al., 1993) or in sensitivity to noxious stimuli because of variations in endogenous opiate systems or adrenergic sensitivity (Lee et al., 1997; Hoffmann et al., 1998).

Interestingly, we only observed effects of the $\mathrm{MC}$ receptor ligands in CCI rats and only in response to cold and mechanical stimulation. From a clinical point of view, this is promising because, in this study, the effects of melanocortins appear to be specific for the allodynia associated with a neuropathic pain state, without altering normal pain sensation by inducing a more general analgesia. This specificity for the hyperalgesia underlying neuropathic pain without affecting baseline pain detection has also been reported for the $\alpha 2$-adrenergic agonist tizanidine (Leiphart et al., 1995).

In summary, in this present study, we show that intrathecally administered MC receptor ligands alter the sensitivity to cold and mechanical stimulation in a rat model for neuropathic pain, the CCI. Our data suggest that these effects are mediated through the MC4 receptor located in the spinal cord. SHU9119 produces profound anti-allodynia, whereas MTII and D-Tyr-MTII increase sensitivity to cold and mechanical sensitivity. We therefore suggest that selective MC4 receptor antagonists may be of value in the treatment of neuropathic pain and that further research into the mechanisms through which the effects of these ligands are exerted is needed.

\section{REFERENCES}

Adan RA, Szklarczyk AW, Oosterom J, Brakkee JH, Nijenhuis WA, Schaaper WM, Meloen RH, Gispen WH (1999) Characterization of melanocortin receptor ligands on cloned brain melanocortin receptors and on grooming behavior in the rat. Eur J Pharmacol 378:249-258.

Attal N, Jazat F, Kayser V, Guilbaud G (1990) Further evidence for "pain-related" behaviours in a model of unilateral peripheral mononeuropathy. Pain 41:235-251.

Backonja M, Arndt G, Gombar KA, Check B, Zimmermann M (1994) Response of chronic neuropathic pain syndromes to ketamine: a preliminary study. Pain [Erratum (1994) 58:433] 56:51-57.

Basbaum AI, Gautron M, Jazat F, Mayes M, Guilbaud G (1991) The spectrum of fiber loss in a model of neuropathic pain in the rat: an electron microscopic study. Pain 47:359-367.

Bennett GJ (1991) The role of the sympathetic nervous system in painful peripheral neuropathy. Pain 45:221-223.

Bennett GJ, Xie YK (1988) A peripheral mononeuropathy in rat that produces disorders of pain sensation like those seen in man. Pain 33:87-107.

Bertolini A, Poggioli R, Ferrari W (1979) ACTH-induced hyperalgesia in rats. Experientia $35: 1216-1217$

Besse D, Lombard MC, Perrot S, Besson JM (1992) Regulation of opioid binding sites in the superficial dorsal horn of the rat spinal cord following loose ligation of the sciatic nerve: comparison with sciatic nerve section and lumbar dorsal rhizotomy. Neuroscience 50:921-933.

Carlton SM, Dougherty PM, Pover CM, Coggeshall RE (1991) Neuroma formation and numbers of axons in a rat model of experimental peripheral neuropathy. Neurosci Lett 131:88-92.

Cechetto DF, Saper CB (1988) Neurochemical organization of the hypothalamic projection to the spinal cord in the rat. J Comp Neurol 272:579-604

Chaplan SR, Bach FW, Pogrel JW, Chung JM, Yaksh TL (1994) Quantitative assessment of tactile allodynia in the rat paw. J Neurosci Methods $53: 55-63$. 
Chizh BA, Dickenson AH, Wnendt S (1999) The race to control pain: more participants, more targets. Trends Pharmacol Sci 20:354-357.

Choi Y, Raja SN, Moore LC, Tobin JR (1996) Neuropathic pain in rats is associated with altered nitric oxide synthase activity in neural tissue. J Neurol Sci 138:14-20.

Cone RD, Lu D, Koppula S, Vage DI, Klungland H, Boston B, Chen W, Orth DN, Pouton C, Kesterson RA (1996) The melanocortin receptors: agonists, antagonists, and the hormonal control of pigmentation. Recent Prog Horm Res 51:287-317.

Dunbar JC, Lu H (1999) Leptin-induced increase in sympathetic nervous and cardiovascular tone is mediated by proopiomelanocortin (POMC) products. Brain Res Bull 50:215-221.

Dunbar JC, Lu H (2000) Proopiomelanocortin (POMC) products in the central regulation of sympathetic and cardiovascular dynamics: studies on melanocortin and opioid interactions. Peptides 21:211-217.

Elias CF, Lee C, Kelly J, Aschkenasi C, Ahima RS, Couceyro PR, Kuhar MJ, Saper CB, Elmquist JK (1998) Leptin activates hypothalamic CART neurons projecting to the spinal cord. Neuron 21:1375-1385.

Felsby S, Nielsen J, Arendt-Nielsen L, Jensen TS (1996) NMDA receptor blockade in chronic neuropathic pain: a comparison of ketamine and magnesium chloride. Pain 64:283-291.

Gispen WH, Wiegant VM, Greven HM, De Wied D (1975) The induction of excessive grooming in the rat by intraventricular application of peptides derived from ACTH: structure-activity studies. Life Sci 17:645-652.

Gispen WH, Buitelaar J, Wiegant VM, Terenius L, De Wied D (1976) Interaction between $\mathrm{ACTH}$ fragments, brain opiate receptors and morphine-induced analgesia. Eur J Pharmacol 39:393-397.

Glazer S, Portenoy RK (1991) Systemic local anesthetics in pain control. J Pain Symptom Manage 6:30-39.

Hama AT, Sagen J, Pappas GD (1994) Morphological characterization of dorsal horn spinal neurons in rats with unilateral constriction nerve injury: a preliminary study. Neurol Res 16:297-304.

Hoffmann O, Plesan A, Wiesenfeld-Hallin Z (1998) Genetic differences in morphine sensitivity, tolerance and withdrawal in rats. Brain Res 806:232-237.

Huang OH, Entwistle ML, Alvaro JD, Duman RS, Hruby VJ, Tatro JB (1997) Antipyretic role of endogenous melanocortins mediated by central melanocortin receptors during endotoxin-induced fever. J Neurosci 17:3343-3351.

Janig W (1985) Systemic and specific autonomic reactions in pain: efferent, afferent and endocrine components. Eur J Anaesthesiol 2:319-346.

Janig W, Levine JD, Michaelis M (1996) Interactions of sympathetic and primary afferent neurons following nerve injury and tissue trauma. Prog Brain Res 113:161-184.

Kajander KC, Xu J (1995) Quantitative evaluation of calcitonin generelated peptide and substance $\mathrm{P}$ levels in rat spinal cord following peripheral nerve injury. Neurosci Lett 186:184-188.

Kim SH, Chung JM (1991) Sympathectomy alleviates mechanical allodynia in an experimental animal model for neuropathy in the rat. Neurosci Lett 134:131-134.

Kingery WS (1997) A critical review of controlled clinical trials for peripheral neuropathic pain and complex regional pain syndromes. Pain 73:123-139.

Kupers RC, Nuytten D, De Castro Costa M, Gybels JM (1992) A time course analysis of the changes in spontaneous and evoked behaviour in a rat model of neuropathic pain. Pain 50:101-111.

Lee DH, Chung K, Chung JM (1997) Strain differences in adrenergic sensitivity of neuropathic pain behaviors in an experimental rat model. NeuroReport 8:3453-3456.

Leiphart JW, Dills CV, Zikel OM, Kim DL, Levy RM (1995) A comparison of intrathecally administered narcotic and nonnarcotic analgesics for experimental chronic neuropathic pain. J Neurosurg 82:595-599.

Mao J, Price DD, Coghill RC, Mayer DJ, Hayes RL (1992) Spatial patterns of spinal cord [14C]-2-deoxyglucose metabolic activity in a rat model of painful peripheral mononeuropathy. Pain [Erratum (1992) 51:389] 50:89-100

Mountjoy KG, Wild JM (1998) Melanocortin-4 receptor mRNA expression in the developing autonomic and central nervous systems. Brain Res Dev Brain Res 107:309-314.
Mountjoy KG, Mortrud MT, Low MJ, Simerly RB, Cone RD (1994) Localization of the melanocortin-4 receptor (MC4-R) in neuroendocrine and autonomic control circuits in the brain. Mol Endocrinol 8:1298-1308.

Ollat H, Cesaro P (1995) Pharmacology of neuropathic pain. Clin Neuropharmacol 18:391-404.

Plantinga LC, Verhaagen J, Edwards PM, Schrama LH, Burbach JP, Gispen WH (1992) Expression of the pro-opiomelanocortin gene in dorsal root ganglia, spinal cord and sciatic nerve after sciatic nerve crush in the rat. Brain Res Mol Brain Res 16:135-142.

Price DD, Bennett GJ, Rafii A (1989) Psychophysical observations on patients with neuropathic pain relieved by a sympathetic block. Pain $36: 273-288$

Ringkamp M, Eschenfelder S, Grethel EJ, Habler HJ, Meyer RA, Janig W, Raja SN (1999) Lumbar sympathectomy failed to reverse mechanical allodynia- and hyperalgesia-like behavior in rats with L5 spinal nerve injury. Pain 79:143-153.

Rosenberg JM, Harrell C, Ristic H, Werner RA, de Rosayro AM (1997) The effect of gabapentin on neuropathic pain. Clin J Pain 13:251-255.

Rowbotham MC, Reisner KL, Fields HL (1991) Both intravenous lidocaine and morphine reduce the pain of postherpetic neuralgia. Neurology 41:1024-1028.

Sandman CA, Kastin AJ (1981) Intraventricular administration of MSH induces hyperalgesia in rats. Peptides 2:231-233.

Schaaper WM, Adan RA, Posthuma TA, Oosterom J, Gispen WH, Meloen RH (1998) Synthesis of cyclic alpha-MSH peptides. Lett Pept Sci 5:205-208

Shir Y, Seltzer Z (1991) Effects of sympathectomy in a model of causalgiform pain produced by partial sciatic nerve injury in rats. Pain 45:309-320.

Smock T, Fields HL (1981) ACTH1-24 blocks opiate-induced analgesia in the rat. Brain Res 212:202-206.

Stevens CW, Kajander KC, Bennett GJ, Seybold VS (1991) Bilateral and differential changes in spinal mu, delta and kappa opioid binding in rats with a painful, unilateral neuropathy. Pain 46:315-326.

Sugimoto T, Bennett GJ, Kajander KC (1990) Transsynaptic degeneration in the superficial dorsal horn after sciatic nerve injury: effects of a chronic constriction injury, transection, and strychnine. Pain 42:205-213.

Tatro JB (1993) Melanocortin receptors of the brain. In: Methods in neurosciences (Conn PM, ed), pp 87-104. New York: Academic.

Tatro JB (1996) Receptor biology of the melanocortins, a family of neuroimmunomodulatory peptides. Neuroimmunomodulation 3:259-284.

Tsou K, Khachaturian H, Akil H, Watson SJ (1986) Immunocytochemical localization of pro-opiomelanocortin-derived peptides in the adult rat spinal cord. Brain Res 378:28-35.

van der Kraan M, Tatro JB, Entwistle ML, Brakkee JH, Burbach JP, Adan RA, Gispen WH (1999) Expression of melanocortin receptors and proopiomelanocortin in the rat spinal cord in relation to neurotrophic effects of melanocortins. Brain Res Mol Brain Res 63:276-286.

Wiegant VM, Gispen WH, Terenius L, De Wied D (1977) ACTH-like peptides and morphine: interaction at the level of the CNS. Psychoneuroendocrinology 2:63-70.

Wiesenfeld-Hallin Z, Hao JX, Xu XJ, Aldskogius H, Seiger A (1993) Genetic factors influence the development of mechanical hypersensitivity, motor deficits and morphological damage after transient spinal cord ischemia in the rat. Pain [Erratum (1994) 57:135] 55:235-241.

Williams DWJ, Lipton JM, Giesecke AHJ (1986) Influence of centrally administered peptides on ear withdrawal from heat in the rabbit. Peptides 7:1095-1100.

Yaksh TL (1999) Spinal systems and pain processing: development of novel analgesic drugs with mechanistically defined models. Trends Pharmacol Sci 20:329-337.

Zerari F, Zouaoui D, Gastard M, Apartis E, Fischer J, Herbrecht F, Cupo A, Cucumel K, Conrath M (1994) Ultrastructural study of delta-opioid receptors in the dorsal horn of the rat spinal cord using monoclonal anti-idiotypic antibodies. J Chem Neuroanat 7:159-170.

Zimmermann M (1983) Ethical guidelines for investigations of experimental pain in conscious animals. Pain 16:109-110. 